\title{
Leptin inhibits 4-aminopyridine- and pentylenetetrazole-induced seizures and AMPAR-mediated synaptic transmission in rodents
}

\author{
Lin Xu, 1,2 Nicholas Rensing, ${ }^{1,2}$ Xiao-Feng Yang, ${ }^{3}$ Hai Xia Zhang, ${ }^{1,2}$ Liu Lin Thio,,1,2 \\ Steven M. Rothman, ${ }^{3}$ Aryan E. Weisenfeld, ${ }^{4}$ Michael Wong, ${ }^{1,2}$ and Kelvin A. Yamada ${ }^{1,2}$ \\ ${ }^{1}$ Department of Neurology and ${ }^{2}$ Hope Center for Neurological Disorders, Washington University School of Medicine, \\ St. Louis, Missouri, USA. '3epartment of Pediatrics, University of Minnesota School of Medicine, Minneapolis, Minnesota, USA. \\ ${ }^{4}$ College of Arts and Sciences, Washington University, St. Louis, Missouri, USA.
}

\begin{abstract}
Leptin is a hormone that reduces excitability in some hypothalamic neurons via leptin receptor activation of the JAK2 and PI3K intracellular signaling pathways. We hypothesized that leptin receptor activation in other neuronal subtypes would have anticonvulsant activity and that intranasal leptin delivery would be an effective route of administration. We tested leptin's anticonvulsant action in 2 rodent seizure models by directly injecting it into the cortex or by administering it intranasally. Focal seizures in rats were induced by neocortical injections of 4-aminopyridine, an inhibitor of voltage-gated $\mathrm{K}^{+}$channels. These seizures were briefer and less frequent upon coinjection of 4-aminopyridine and leptin. In mice, intranasal administration of leptin produced elevated brain and serum leptin levels and delayed the onset of chemical convulsant pentylenetetrazoleinduced generalized convulsive seizures. Leptin also reduced neuronal spiking in an in vitro seizure model. Leptin inhibited $\alpha$-amino-3-hydroxy-5-methyl-4-isoxazole proprionic acid (AMPA) receptor-mediated synaptic transmission in mouse hippocampal slices but failed to inhibit synaptic responses in slices from leptin receptor-deficient $d b / d b$ mice. JAK2 and PI3K antagonists prevented leptin inhibition of AMPAergic synaptic transmission. We conclude that leptin receptor activation and JAK2/PI3K signaling may be novel targets for anticonvulsant treatments. Intranasal leptin administration may have potential as an acute abortive treatment for convulsive seizures in emergency situations.
\end{abstract}

\section{Introduction}

There is a pressing need for new anticonvulsants for children and adults with medically refractory epilepsy. Neuropeptides such as neuropeptide Y (NPY) and galanin are promising because they have anticonvulsant effects in seizure models (1-5). However, the potential of neuropeptides as anticonvulsants remains unexploited except for adrenocorticotropic hormone, an accepted treatment for some childhood epilepsies (6). One factor limiting the clinical utility of neuropeptides such as NPY and galanin is that they are not suited for peripheral administration because they do not cross the blood-brain barrier. Thus, the peptide leptin may have a clinical advantage because it has anticonvulsant properties and crosses the blood-brain barrier via a transport system (7). Leptin is potentially easy to administer because i.n. leptin administration produces rapid, substantial increases in serum, cerebrospinal fluid, and brain leptin levels $(8,9)$.

Nonstandard abbreviations used: ACSF, artificial cerebrospinal fluid; AMPA, $\alpha$-amino-3-hydroxy-5-methyl-4-isoxazole proprionic acid; AMPAR, AMPA receptor; 4AP, 4-aminopyridine; BK channel, large-conductance calcium-activated neuronal potassium channel; CNQX, 6-cyano-7-nitroquinoxaline-2,3-dione; D-APV, D-2-amino5 -phosphonovaleric acid; EPSC, excitatory postsynaptic current; fEPSP, field excitatory postsynaptic potential; $\mathrm{K}_{\mathrm{ATP}}$, ATP-sensitive $\mathrm{K}^{+}$; LPC, lysophosphatidylcholine; LTD, long-term depression; LTP, long-term potentiation; NMDAR, $N$-methyl-D-aspartate receptor; PTZ, pentylenetetrazole; STP, short-term potentiation.

Conflict of interest: The authors have declared that no conflict of interest exists. Citation for this article: J. Clin. Invest. 118:272-280 (2008). doi:10.1172/JCI33009.
Leptin receptor expression has been reported in the hippocampus and neocortex (10-12), but its functional role is poorly understood. Recent studies in primary neuronal cultures and hippocampal slices have characterized some of leptin's anticonvulsant properties beyond its role in regulating energy homeostasis. In these studies leptin suppressed epileptiform-like bursting and elevations in intracellular calcium under low extracellular magnesium conditions by opening large-conductance calciumactivated neuronal potassium (BK) channels $(11,13,14)$. Leptin also induces long-term depression (LTD) under these conditions (15). These results, combined with our and others' observations that ketogenic diets elevate serum leptin levels in rodents $(16,17)$, motivated us to try to link leptin to the anticonvulsant effects of ketogenic diets (i.e., high-fat, low-carbohydrate, and adequateprotein diets) sometimes used to treat intractable epilepsy (18). We hypothesized that leptin may contribute to some of the anticonvulsant effects of ketogenic diets.

We recognize that leptin may be a proconvulsant. For example, leptin increases spike frequency in a penicillin model of epileptiform activity (19). In addition, leptin enhances $N$-methylD-aspartate receptor (NMDAR) activity by activating PI3K and MAPK $(15,20,21)$. Leptin-induced activation of PI3K may enhance AMPA receptor (AMPAR) synaptic transmission because PI3K increases the surface expression of AMPARs $(22,23)$. Leptin also converts short-term potentiation (STP) into long-term potentiation (LTP) (21). Despite these effects, leptin produces a 
A

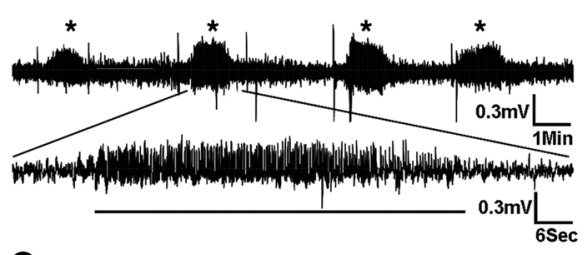

C

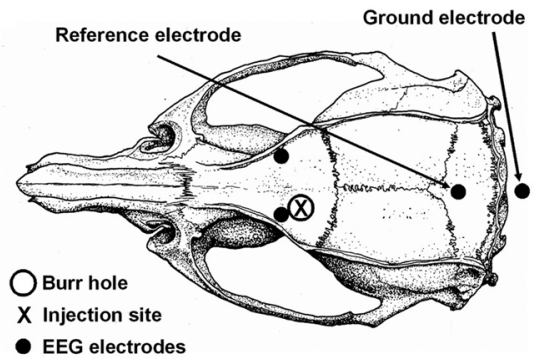

B

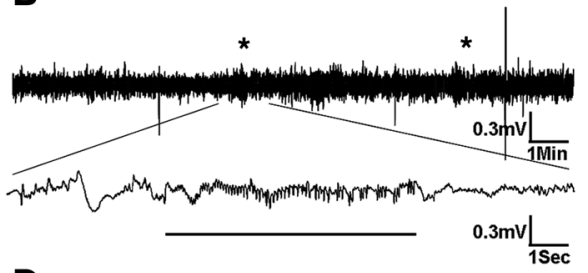

D

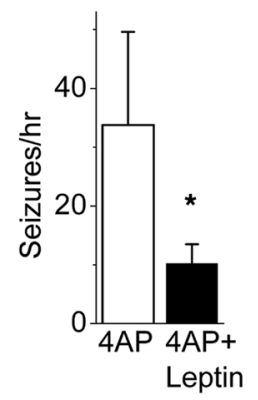

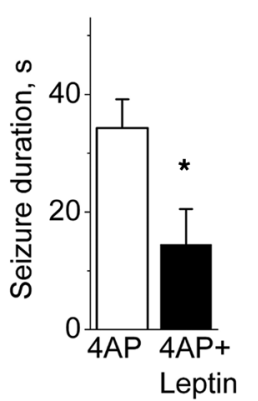

Figure 1

Leptin inhibits in vivo focal neocortical seizures in rats induced by 4AP injections into the left motor cortex. (A) Top trace: 15-minute EEG segment recorded from the frontal area ipsilateral to the injection site 45 minutes after the injection of $12.5 \mathrm{nmol} 4 \mathrm{AP}$. Asterisks indicate 4 individual seizures. Bottom trace: a 1-minute seizure at an expanded time base to illustrate the electrographic details of the seizure (underlined). (B) Top trace: 15-minute EEG segment recorded 45 minutes after the injection of $12.5 \mathrm{nmol} 4 \mathrm{AP}$ plus $39 \mathrm{pmol}$ leptin shows 2 shorter, lower-amplitude seizures (asterisks). Bottom trace: a 10-second seizure shown at an expanded time base (underlined). Note the different time calibration compared with A. (C) Location of the burr hole, injection site, and EEG electrodes relative to standard landmarks. (D) Leptin reduced the frequency and duration of 4APinduced seizures. Seizure frequency (left) and duration (right) in rats injected with $12.5 \mathrm{nmol} 4 \mathrm{AP}$ alone (white bars; $n=5$ ) or $12.5 \mathrm{nmol}$ plus 39 pmol leptin (black bars; $n=5$ ). Seizure frequency and duration for each rat were determined from the 60 minutes of EEG recordings collected between 30 and 90 minutes after 4AP injection. ${ }^{*} P<0.02$ for frequency vs. 4AP alone and ${ }^{*} P<0.001$ for duration vs. 4AP alone (unpaired $t$ test).

small decrease in basal AMPAR-mediated synaptic currents (21). Whether PI3K activation underlies this effect is unknown.

In the experiments described below, we characterize the effects of leptin on neuronal excitability. First, we determined whether leptin is an anticonvulsant in an in vivo rat model of focal neocortical seizures induced by 4-aminopyridine (4AP) (24). Second, we determined whether i.n. leptin administration inhibits generalized convulsions induced by pentylenetetrazole (PTZ) and increases brain leptin levels. Finally, we investigated whether leptin inhibits AMPAR-mediated synaptic transmission in hippocampal slices via a leptin receptor-mediated mechanism involving JAK and PI3K signaling.

\section{Results}

Leptin shortens and reduces $4 A P$-induced neocortical seizure in rats. Direct cortical injection of $12.5 \mathrm{nmol} 4 \mathrm{AP}$ alone in rats consistently induced recurrent seizures typically lasting about 1 minute, within 30 minutes of injection (24) (Figure 1). 4AP, a nonspecific inhibitor of voltage-gated $\mathrm{K}^{+}$channels, induced seizures that were easy to identify electrographically by their discrete onset, stereotypically evolving amplitude and frequency features, and abrupt cessation (Figure 1A). Electrographic seizures in rats coinjected with $12.5 \mathrm{nmol} 4 \mathrm{AP}+39 \mathrm{pmol}$ leptin were of lower amplitude and noticeably briefer and less frequent than in rats injected with $12.5 \mathrm{nmol}$ 4AP plus vehicle (Figure 1, B and D). Leptin decreased

the cumulative seizure duration, defined as the total duration of ictal activity between 30 and 90 minutes after $4 \mathrm{AP}$ injection, from $19 \pm 9.3 \mathrm{~min}-$ utes $(n=5)$ to $2.6 \pm 1.7$ minutes $(n=5$; $P<0.001$, unpaired $t$ test). Leptin did not eliminate interictal spikes.

Intranasal leptin administration and PTZ-induced seizures. PTZ, a $\mathrm{GABA}_{\mathrm{A}}$ receptor antagonist, is a chemical convulsant that reliably produces generalized convulsive seizures (clonic-tonic) when administered i.p. The rodent PTZ seizure model is a standard animal seizure model according to the $\mathrm{NIH} /$ National Institute of Neurological Disorders and Stroke Anticonvulsant Drug Development Program (25), possessing a quantifiable seizure onset latency, easily recognized behavioral seizures, and predictive value for anticonvulsant efficacy against generalized seizures in humans. To determine if leptin inhibits seizures in this model, we gave leptin i.n. to CD-1 mice 30 minutes before giving $75 \mathrm{mg} / \mathrm{kg}$ PTZ i.p. Rapid progression from myoclonus to maximum severity generalized clonic-tonic seizures (and often death) in every mouse within 10 minutes obviated the need to grade seizure severity in this model. A leptin dose of $800 \mu \mathrm{g} / \mathrm{kg}$ more than doubled the seizure latency compared with control (Figure 2A). Leptin doses of 8 and $80 \mu \mathrm{g} / \mathrm{kg}$ also increased seizure latency, but the differences were not statistically significant (data not shown). Leptin was not a proconvulsant at the 3 doses used.

Brain and serum leptin levels after i.n. leptin administration. As described previously $(8,9)$, we observed that serum and brain leptin levels increased 30 minutes after i.n. leptin administration. Significant increases in serum and brain leptin levels occurred 30 minutes after administration of $800 \mu \mathrm{g} / \mathrm{kg}$ leptin i.n. (Figure 2, B and C). All brains of mice that received $800 \mu \mathrm{g} / \mathrm{kg}$ leptin showed leptin levels above $20 \mathrm{pg} / \mathrm{mg}$ protein, which we determined to be the lowest level of detection with this assay. Leptin doses of 8 and $80 \mu \mathrm{g} / \mathrm{kg}$ produced smaller increases in serum and brain leptin levels; at both doses, brain leptin was near the detection threshold of $20 \mathrm{pg} / \mathrm{mg}$ protein. All vehicle-treated mice had brain leptin levels below $20 \mathrm{pg} / \mathrm{mg}$ protein.

Leptin inhibits synaptic responses in mouse hippocampal slices. In hippocampal slices, leptin enhances NMDAR-mediated responses and converts STP to LTP (21). This effect was unlikely to have accounted for our observation that leptin reduces 4AP-induced seizures. However, Shanley et al. (21) also observed modest, reversible inhibition of AMPAR-mediated excitatory postsynaptic currents (EPSCs) without changes in the cell input resistance, which raises the possibility that AMPAR inhibition could partially explain leptin's anticonvulsant action. The absence of reduced input resistance would argue against increased tonic activity of ion channels such as BK or ATP-sensitive $\mathrm{K}^{+}\left(\mathrm{K}_{\mathrm{ATP}}\right)$ 

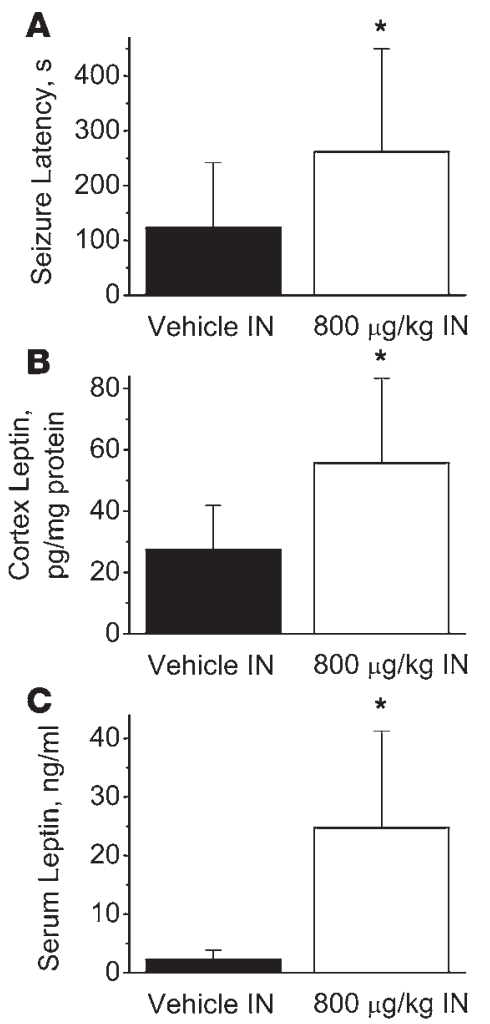

channels. Therefore, we examined the effect of leptin on CA1 stratum radiatum field excitatory postsynaptic potentials (fEPSPs) evoked by Schaffer collateral stimulation in hippocampal slices. Fifteen minutes after bath-applied $0.6 \mathrm{nM}$ leptin, a reversible reduction of $81 \% \pm 6 \%$ ( $n=7$ slices, 6 mice) occurred in the slope of the fEPSP (Figure 3, A and B). Leptin produced a U-shaped, concentration-dependent inhibition of the fEPSP slope; $50 \mathrm{nM}$ leptin produced only a $4 \% \pm 7 \%$ reduction in the slope ( $n=6$ slices, 2 mice) (Figure 3C).

Leptin selectively inbibits the AMPAR component of the fEPSP and increases paired pulse facilitation. To evaluate whether leptin differentially inhibited AMPARs and NMDARs, we pharmacologically isolated these components of the fEPSP and examined leptin's effects. The CA1 fEPSP slope in nominally $\mathrm{Mg}^{2+}$-free (no added) artificial cerebrospinal fluid (ACSF) was $97.0 \% \pm 4 \%$ ( $n=4$ slices, 1 mouse) of the baseline response obtained in standard ACSF. In the

\section{Figure 3}

Leptin inhibits CA1 fEPSPs in mouse hippocampal slices. (A) Representative tracings of Schaffer collateral evoked fEPSPs recorded in CA1 at baseline during perfusion of ACSF (Baseline), after a 20minute perfusion with $0.6 \mathrm{nM}$ leptin (Leptin), and after a 30-minute washout with ACSF (Recovery). Calibration: $2 \mathrm{~ms}, 0.1 \mathrm{mV}$. (B) Time course of the fEPSP slope demonstrates the inhibition of fEPSP during a 20-minute application of $0.6 \mathrm{nM}$ leptin (indicated by the bar), which almost completely recovers after a 30 -minute washout with ACSF ( $n=7$ slices, 6 mice). fEPSP slopes at each time point were normalized to the slope of the baseline fEPSPs, which is indicated by the dotted line. Only every third point is shown for clarity. (C) U-shaped concentration-response curve of leptin inhibition of the fEPSP slope demonstrates maximal inhibition at $0.6 \mathrm{nM}$ and minimal inhibition at 0.006 and $50 \mathrm{nM}$ leptin ( $n=6$ slices, 2 mice).

\section{Figure 2}

Intranasal leptin inhibits in vivo PTZ-induced generalized convulsive seizures and elevates serum and brain leptin levels in mice. (A) In 6- to 8 -week-old CD-1 mice, $800 \mu \mathrm{g} / \mathrm{kg}$ leptin $(n=15)$ given i.n. 30 minutes before the i.p. injection of $75 \mathrm{mg} / \mathrm{kg}$ PTZ significantly increased the latency to behaviorally assessed generalized clonic-tonic seizures. ${ }^{\star} P<0.002$ compared with mice that received vehicle $(n=16)$. (B) Cortex leptin per milligram of cortex protein $\left({ }^{*} P<0.001\right)$. (C) Serum leptin concentrations increased significantly $\left({ }^{\star} P<0.0001\right)$ after $800 \mu \mathrm{g} / \mathrm{kg}$ leptin i.n. compared with vehicle. The Mann-Whitney $U$ test was used for the statistical analysis.

same slices, the fEPSP slope was reduced to $26 \% \pm 6 \%$ of the baseline response after the addition of $10 \mu \mathrm{M} 6$-cyano-7-nitroquinoxaline-2,3-dione (CNQX) to the ACSF to block the AMPAR-mediated component of the fEPSP; the fEPSP slope was further reduced to $5 \% \pm 2 \%$ of the baseline response after application of ACSF with both $10 \mu \mathrm{M}$ CNQX and $50 \mu \mathrm{M}$ D-2-amino-5-phosphonovaleric acid (D-APV, an NMDAR antagonist). In ACSF with $50 \mu \mathrm{M}$ D-APV, $0.6 \mathrm{nM}$ leptin inhibited the isolated AMPAR component of the fEPSP; the fEPSP slope after 30 minutes of leptin application was $26 \% \pm 2 \%$ of baseline ( $n=4$ slices, 2 mice; Figure $4 \mathrm{~A}$ ). In $\mathrm{Mg}^{2+}$ free ACSF with $10 \mu \mathrm{M} C N Q X$, leptin did not affect the isolated NMDAR component of the fEPSP (Figure 4B).

The selective inhibition of the AMPAR component of the fEPSP generally supports a postsynaptic mechanism. To further distinguish between a pre- and postsynaptic site of action, we examined the effect of leptin on paired pulse facilitation. We compared the paired pulse ratio (P2/P1, where $\mathrm{P} 1$ is the slope of the first fEPSP and P2 is the slope of the second fEPSP) at baseline and after applying $0.6 \mathrm{nM}$ leptin for 20 minutes. Leptin reduced the slope of both fEPSPs in a pair (Figure 4C, arrows) and slightly but significantly increased the paired pulse ratio (Figure 4D), which suggested an additional presynaptic inhibitory mechanism.

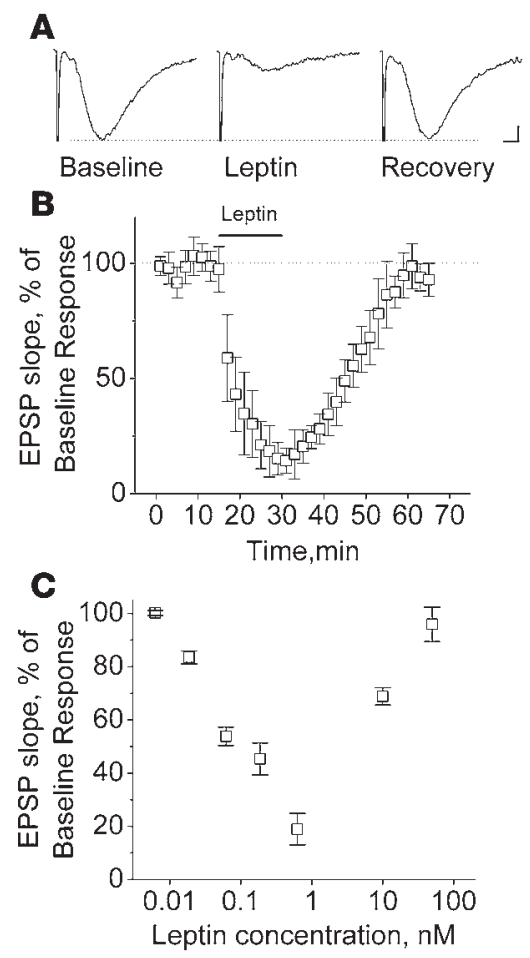


A

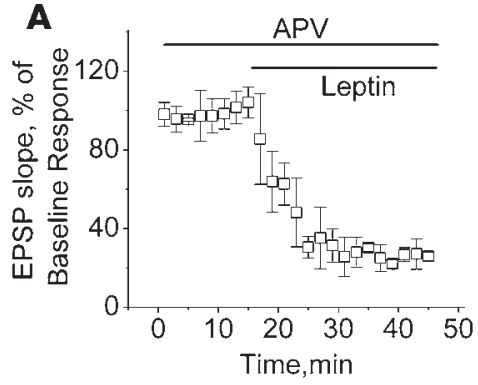

C

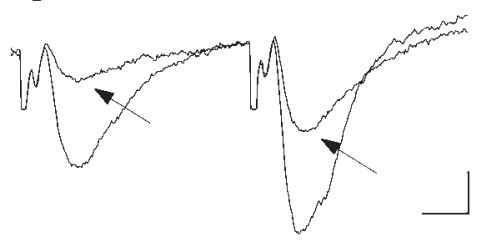

B

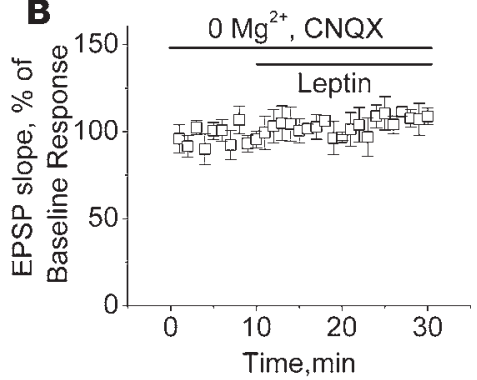

D

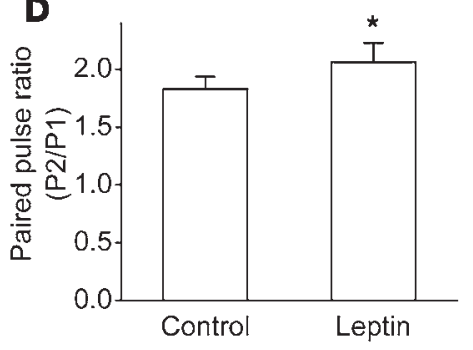

Figure 4

Leptin selectively inhibits the AMPAR-mediated component of the CA1 field excitatory postsynaptic potentials (fEPSPs) in mouse hippocampal slices. (A) Leptin inhibited the AMPAR component of the CA1 fEPSP. Time course of the fEPSP slope for the AMPAR component after bath-applied $0.6 \mathrm{nM}$ leptin as indicated by the bar ( $n=4$ slices, 2 mice). The AMPAR component was isolated by adding the $N$-methyl-D-aspartate (NMDA) antagonist D-APV $(50 \mu \mathrm{M})$ as indicated by the bar. (B) In contrast, leptin did not inhibit the NMDAR component of the CA1 fEPSP. Time course of the fEPSP slope for the NMDA component after bath-applied $0.6 \mathrm{nM}$ leptin as indicated by the bar ( $n=6$ slices, 4 mice). The NMDAR component was isolated by adding the AMPAR antagonist CNQX $(10 \mu \mathrm{M})$ in $\mathbf{M g}^{2+-f r e e} \mathrm{ACSF}$. Data in $\mathbf{A}$ and $\mathbf{B}$ were analyzed as in Figure 3B. The bars indicate when $\mathrm{Mg}^{2+}$-free ACSF and leptin were applied. (C and D) Leptin enhances paired-pulse facilitation. (C) Superimposed representative pairs of CA1 fEPSPs from the same slice demonstrate fEPSP inhibition and increased paired pulse facilitation in $0.6 \mathrm{nM}$ leptin (arrows). Interstimulus interval: $25 \mathrm{~ms}$; calibration: $4 \mathrm{~ms}, 0.2 \mathrm{mV}$. (D) Cumulative data from 5 slices ( 5 mice) comparing the paired pulse facilitation ratio $(P P F=P 2 / P 1$, where $P 1$ is the slope of the first fEPSP and P2 is the slope of the second fEPSP) before and after the application of $0.6 \mathrm{nM}$ leptin for 20 minutes ( ${ }^{\star} P<0.02$, paired $t$ test).

Given that the above results do not definitively support a presynaptic mechanism, we used whole-cell voltage clamp recordings from CA1 pyramidal neurons to examine the effect of leptin on AMPAR- and NMDAR-mediated EPSCs. Leptin inhibited AMPAR-mediated EPSCs and fEPSPs in a similar manner, except that only partial recovery occurred with washout (Figure $5 \mathrm{~A})$. Leptin at $0.6 \mathrm{nM}$ reduced the amplitude of AMPAR EPSCs recorded at $-70 \mathrm{mV}$ by $56 \% \pm 20 \%(n=9)$; a lower and a higher concentration of leptin produced no change (Figure 5B). In 2 other cells, $0.6 \mathrm{nM}$ leptin did not inhibit the AMPAR-mediated EPSC; these cells were not included in the amplitude analysis. Leptin produced a larger increase in paired-pulse facilitation of AMPAR-mediated EPSCs than in fEPSPs (Figure 5C). In 8 of 11 cells, leptin also significantly lengthened the EPSC latency from $3.2 \pm 0.5$ to $4.3 \pm 1.0 \mathrm{~ms}(P<0.02$, paired $t$ test $)$, with partial recovery to baseline on leptin washout. Leptin clearly inhibited the EPSC in 2 of the 3 cells that exhibited no change in EPSC latency. The mean amplitude of NMDAR-mediated EPSCs recorded at $+20 \mathrm{mV}$ in ACSF containing $2 \mathrm{mM} \mathrm{CaCl}_{2}, 1 \mathrm{mM} \mathrm{MgCl}_{2}$, and $10 \mu \mathrm{M}$ 2,3-dihydroxy-6-nitro-7-sulfamoyl-benzo[f]quinoxaline-2,3-

dione (NBQX) - a selective AMPAR antagonist - was $97 \% \pm 3.2 \%$ of the control $(n=5$ cells $)$. Together these results suggest that leptin inhibits AMPAR-mediated synaptic transmission pre- and postsynaptically.

Leptin inbibits low magnesium-induced spiking in cultured hippocampal neurons. To determine whether leptin reduces neuronal hyperexcitability at concentrations comparable with those that inhibit AMPAergic EPSPs and EPSCs in slices, we examined the effect of leptin on the bursts of action potentials induced in cultured hippocampal neurons by nominally $\mathrm{Mg}^{2+}$-free extracellular solution $(26,27)$. Cultured hippocampal neurons generally fire isolated action potentials when $\mathrm{Mg}^{2+}$ is present in the extracellular solution. When the extracellular solution contains no added $\mathrm{Mg}^{2+}$, the neurons fire bursts of action potentials superimposed on a depolarizing wave that resembles a paroxysmal depolarizing shift (Figure 6A). Leptin decreased action potential bursting (Figure 6B, $1 \mathrm{nM}$ leptin), which partially reverted to baseline spike frequency after leptin washout (Figure 6C). Cumulative data show that 1 and $10 \mathrm{nM}$ leptin, but not $0.1 \mathrm{nM}$ leptin, significantly decreased action potential bursting on the basis of a comparison of spike frequency in the same neuron before and after leptin application (Figure 6D). Thus, leptin decreases neuronal hyperexcitability in cultured hippocampal neurons in the same concentration range that decreases AMPAR-mediated EPSCs in hippocampal slices.

In separate experiments we examined whether leptin alters neuronal input resistance or action potential properties. We used cultured hippocampal neurons because they are more compact electrically, which makes leptininduced changes in input resistance easier to detect. Leptin concentrations of $0.1,1$, and $10 \mathrm{nM}$ had no effect on neuronal input resistance or action potential properties (threshold, amplitude, or duration; see Supplemental Table 1; supplemental material available online with this article; doi:10.1172/JCI33009DS1).

$J A K$ and PI $3 \mathrm{~K}$ inhibitors prevent leptin inhibition of fEPSP. Leptin receptors are class I cytokine receptors that signal via association with JAKs. When leptin binds to the long form of the leptin receptor, Ob-Rb, JAK2 is activated and both proteins are subsequently phosphorylated, which results in the recruitment and activation of downstream signaling pathways in hematopoietic, adipocyte, pancreatic, and muscle cells $(28,29)$. Evidence indicates that JAK/PI3K signaling is important in neurons (30-32), and leptin-mediated effects in neurons have been shown to be inhibited by JAK inhibitors (33-35) and PI3K inhibitors $(11,36)$.

Therefore, we examined whether JAK and PI3K inhibitors prevent leptin from decreasing CA1 fEPSPs. After baseline EPSP recordings were obtained, application of the JAK2 inhibitor AG490 alone (20 $\mu \mathrm{M}$; 45-60 minutes) had no effect on the fEPSP slope (data not shown). However, preincubating slices with AG490 for at least 3 hours prevented $0.6 \mathrm{nM}$ leptin from inhibiting CA1 fEPSPs (Figure 7A). We also used 2 structurally unrelated PI3K inhibitors, LY294002 and wortmannin, to investigate whether PI3K activation is necessary for leptin's effect. Application of LY294002 $(16 \mu \mathrm{M})$ or wortmannin $(50 \mathrm{nM})$ alone had no effect on baseline fEPSP slope (data not shown). Preincubation with either agent for at least 3 hours completely 


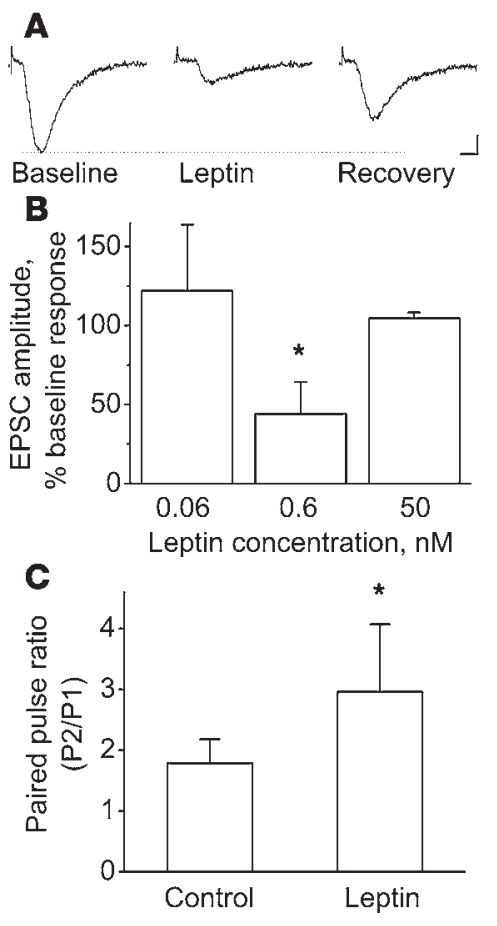

prevented leptin-induced inhibition of fEPSPs (Figure 7, B and C). These data indicate that leptin-induced inhibition of CA1 hippocampal AMPAR synaptic responses requires activation of the JAK2/PI3K signaling pathway.

Effects of leptin in $d b / d b$ mice. Leptin acts systemically to orchestrate complex biological effects through its specific cellular receptor. As mentioned above, the long form of Ob-Rb is capable of full signal transduction. To address whether leptin inhibition of AMPAR-mediated synaptic responses requires leptin receptor activation, we compared the effects of leptin on CA1 fEPSPs in hippocampal slices from $d b / d b$ mice, which are Ob-Rb deficient (37), and from wild-type C57BLKS/J mice, the background strain of $d b / d b$ mice. In slices from C57BLKS/J mice, leptin inhibited synaptic responses as observed in CD-1 mice; CA1 fEPSP slopes were $34 \% \pm 3 \%$ ( $n=6$ slices, 3 mice) of baseline after perfusion with $0.6 \mathrm{nM}$ leptin for 30 minutes (Figure 8). However, in slices

\section{Figure 6}

Leptin inhibits low magnesium-induced spiking in cultured mouse hippocampal neurons. (A) Whole-cell patch recordings from cultured hippocampal neurons in current clamp configuration spontaneously fire action potentials in nominally magnesium-free external solution. Baseline membrane potential: $-57 \mathrm{mV}$. Calibration for A1-A3: $10 \mathrm{~s}$, $30 \mathrm{mV}$. (B) Leptin (1 $\mathrm{nM}$ ) reduces action potential firing frequency by $30 \%-40 \%$. (C) Action potential firing recovers close to baseline frequency after leptin washout. (D) Cumulative data comparing spike frequency in low magnesium before (filled squares) and after (open squares) application of different leptin concentrations. Each filled and open symbol connected by a line represents 1 cell and its firing frequency before and after leptin. Therefore, each line represents 1 matched data pair; some data points are superimposed on each other. The mean \pm SD values are presented beside each data set with a larger symbol. A significant reduction in spike frequency was produced by $1.0 \mathrm{nM}(n=13$ cells $)$ and $10 \mathrm{nM}(n=11$ cells $)$, but not by $0.1 \mathrm{nM}$ ( $n=12$ cells) leptin (paired $t$ test).

\section{Figure 5}

Leptin inhibits AMPAR-mediated EPSCs obtained from voltageclamped CA1 pyramidal neurons in mouse hippocampal slices. (A) Representative tracings of Schaffer collateral evoked whole-cell EPSCs recorded from a voltage-clamped CA1 neuron at $-70 \mathrm{mV}$ at baseline during perfusion of ACSF containing $2 \mathrm{mM} \mathrm{CaCl}_{2}$ and $1 \mathrm{mM}$ $\mathrm{MgCl}_{2}$ (Baseline), after a 10-minute perfusion with $0.6 \mathrm{nM}$ leptin (Leptin), and after a 20-minute washout with ACSF (Recovery). Calibration: $5 \mathrm{~ms}, 25 \mathrm{pA}$. (B) Leptin inhibited AMPAR-mediated EPSCs with a U-shaped dose-response relation. Peak amplitudes of AMPAR-mediated EPSCs after a 10-minute perfusion with various leptin concentrations expressed as a percentage of the peak amplitude of the baseline EPSC ( $n=5-9$ cells). ${ }^{*} P<0.001$ for 0.6 vs. $0.06 n M$ and ${ }^{*} P<0.01$ for 0.6 vs. $50 \mathrm{nM}$ leptin (ANOVA followed by Tukey-Kramer's test for multiple comparisons). (C) Leptin-enhanced paired pulse facilitation. The paired-pulse ratio was calculated as in Figure 4 by using peak amplitudes of pairs of EPSCs evoked with an interstimulus interval of 25 milliseconds in $0.6 \mathrm{nM}$ leptin. $n=8$ cells, ${ }^{*} P<0.02$ (paired $t$ test).

from $d b / d b$ mice, leptin did not alter CA1 fEPSP slopes; the slopes were $93 \% \pm 12 \%$ ( $n=10$ slices, 3 mice) of baseline after application of $0.6 \mathrm{nM}$ leptin for 30 minutes. This result indicates that $\mathrm{Ob}-\mathrm{Rb}$ activation is necessary for leptin to inhibit AMPAR-mediated CA1 hippocampal synaptic responses.

\section{Discussion}

Leptin is an anticonvulsant in a focal and a generalized seizure model. The ketogenic diet, an effective anticonvulsant therapy, elevates serum leptin levels in rodents $(16,17)$. Leptin reduces neuronal excitability and epileptiform activity in vitro (11), and Durakoglugil et al. (15) postulated, based on leptin's actions in vitro, that leptin is an endogenous anticonvulsant. Accordingly, we found that leptin decreased the frequency and duration of 4AP-induced focal neocortical seizures in rats. In addition, i.n. administered leptin $(800 \mu \mathrm{g} / \mathrm{kg})$ elevated brain leptin and increased the latency of PTZ-induced generalized seizures. Two lower doses of leptin (8 and $80 \mu \mathrm{g} / \mathrm{kg}$ ) produced a trend toward increased PTZ-induced seizure latency without a consistent elevation in brain leptin with our assay. We speculate that the lower leptin doses produce higher

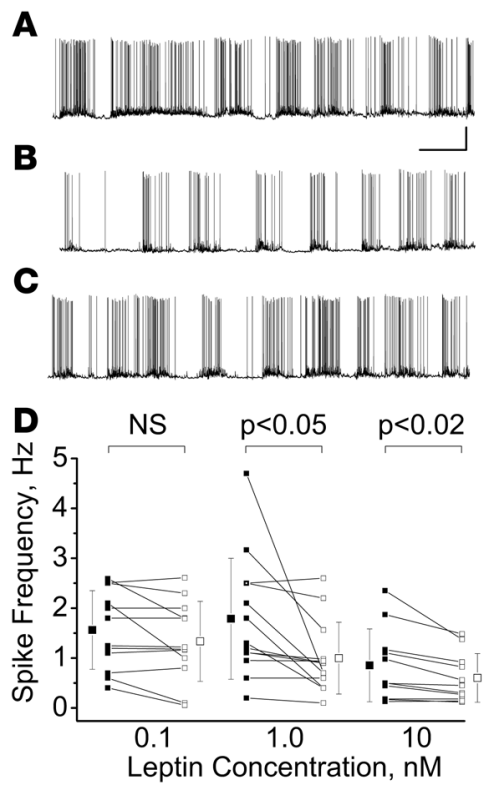



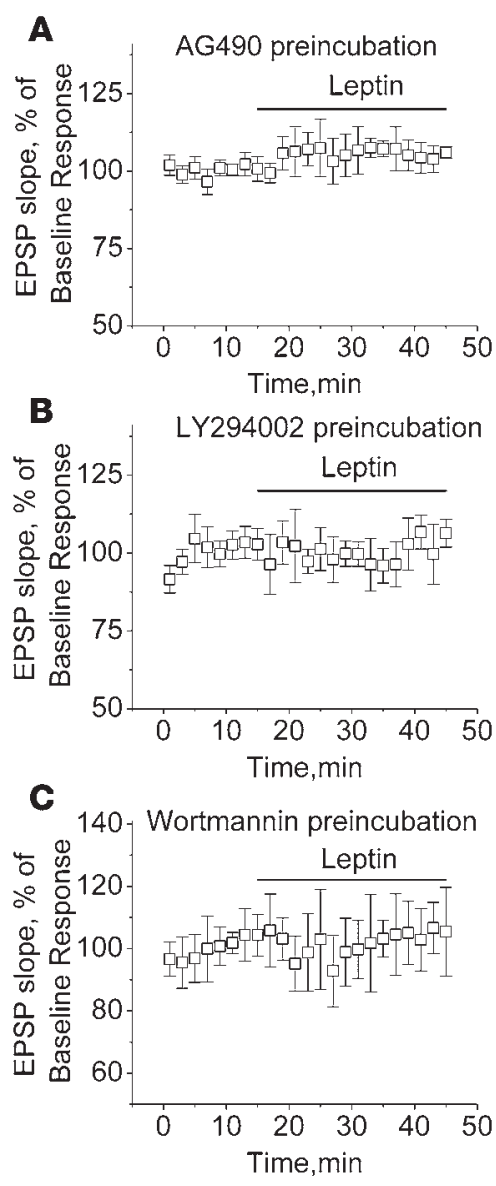

than basal brain leptin levels, which are below the detection level of the assay, yet impart some anticonvulsant effect not robust enough to produce a statistically significant group effect. We conclude that leptin is an anticonvulsant against acute seizures induced by 2 convulsants with different mechanisms of action and against both focal and generalized seizures in vivo. Whether leptin is effective against sporadic seizures in chronic epilepsy is unclear and requires further study. It is possible that leptin counters acute emergent seizures but is not an effective anticonvulsant when administered chronically. Importantly, we found no evidence that leptin has proconvulsant effects, despite observations that raise the possibility that leptin might increase neuronal excitability and worsen seizures $(19,21)$.

Leptin inhibits AMPAergic synaptic responses and low magnesiuminduced spiking. We found that a narrow range of leptin concentrations inhibit AMPAR-mediated synaptic responses. A maximally effective leptin concentration of $0.6 \mathrm{nM}$ inhibited AMPAR-mediated CA 1 fEPSP by $80 \%$ and CA1 EPSCs by $60 \%$; lower and higher concentrations produced less inhibition. Results similar to ours were reported by Shanley et al. (21), who found that $50 \mathrm{nM}$ leptin inhibits AMPAR-mediated CA1 EPSCs by $20 \%$; however, they did not report the effects of lower leptin concentrations. Other effects of leptin, such as those on the modulation of CA1 LTP in hippocampal slices $(38,39)$, the medial perforant path LTP in vivo (40), and intracellular $\mathrm{Ca}^{2+}(11,39)$, also showed a U-shaped dependence on leptin concentration. These results suggest that the effects of leptin are highly regulated and complex.

\section{Figure 7}

Leptin inhibition of CA1 fEPSPs in mouse hippocampal slices depends on JAK2 and PI3K activation. The JAK2 inhibitor AG490 and the PI3K inhibitors LY294002 and wortmannin prevented leptin-induced fEPSP inhibition. Time course of CA1 fEPSP slopes after the application of $0.6 \mathrm{nM}$ leptin as indicated by the bar in slices pretreated for at least 3 hours in $20 \mu \mathrm{M} \mathrm{AG490} \mathrm{(} n=5$ slices, 3 mice) (A), $16 \mu$ M LY294002 ( $n=7$ slices, 2 mice) (B), or $50 \mathrm{nM}$ wortmannin ( $n=6$ slices, 2 mice) (C). Data were analyzed as in Figure 3B.

Our results did not allow us to determine which of leptin's many potentially anticonvulsant effects contribute to its anticonvulsant effect in vivo. In addition to the inhibition of AMPAR-mediated synaptic transmission, leptin's anticonvulsant effect may result from NMDAR inhibition (39) or BK channel activation $(11,13,36)$. Our results are consistent with those of a model in which the inhibition of AMPAR-mediated synaptic transmission contributes to leptin's anticonvulsant effect at low (nanomolar) concentrations, and other mechanisms contribute at higher concentrations. We found that low (nanomolar) leptin concentrations inhibit experimentally induced bursting in cultured neurons (Figure 6). This result is consistent with the inhibition of AMPAR-mediated synaptic transmission contributing to leptin's anticonvulsant effect. However, we expect leptin to have a narrow therapeutic range as an anticonvulsant in vivo if the inhibition of AMPAR-mediated synaptic transmission were its only anticonvulsant mechanism based on the U-shape concentration response curve. However, leptin does not appear to have a narrow therapeutic range as an anticonvulsant in vivo. Thus, we predict that other mechanisms, such as the induction of LTD (15), the activation of BK $(11,13$, 36 ), and the activation of $K_{\text {ATP }}$ channels (41), may contribute to leptin's anticonvulsant effects at higher leptin doses. These effects of leptin require 100-fold higher leptin concentrations than needed to inhibit AMPAR-mediated synaptic transmission.

Differential effects of leptin on AMPAR and NMDAR responses. Leptin can modulate AMPAR-mediated synaptic responses by altering NMDAR-dependent forms of long-term synaptic plasticity. In the hippocampus, leptin enhances LTP (38-40), converts STP into LTP (21), and induces a novel form of LTD (15).

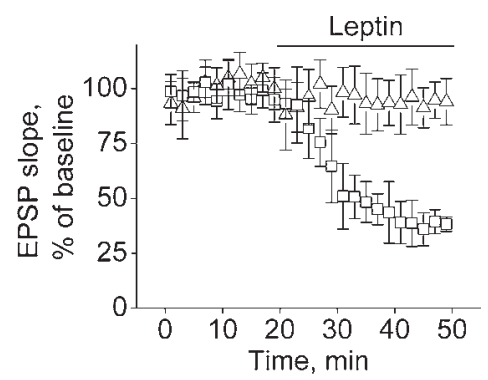

\section{Figure 8}

Leptin inhibition of CA1 field excitatory postsynaptic potentials (fEPSPs) in mouse hippocampal slices depends on the long form of the leptin receptor. Leptin did not inhibit fEPSPs in hippocampal slices obtained from leptin receptor (Ob-Rb)-deficient $d b / d b$ mice, but did inhibit fEPSPs in slices from wild-type C57BLKS/J mice. The time course of CA1 fEPSPs after the application of $0.6 \mathrm{nM}$ leptin is indicated by the bar for slices from $d b / d b$ mice ( $n=6$ slices, 3 mice) (triangles) and C57BLKS/J mice ( $n=10$ slices, 3 mice) (squares). Data were analyzed as in Figure 3B. 
The leptin-induced inhibition of AMPAergic synaptic responses reported herein is not a form of NMDAR-dependent long-term synaptic plasticity because the inhibition reverses on leptin removal. The inhibition we observed occurred independently of NMDAR activation because it occurred when $\mathrm{Mg}^{2+}$ or D-APV blocked NMDARs. Moreover, to inhibit AMPAergic synaptic responses, we used nearly 100 -fold lower leptin concentrations than required to enhance NMDAR responses or modulate longterm synaptic plasticity $(15,21)$.

The increase in paired-pulse facilitation of CA1 fEPSPs and EPSCs suggests that leptin inhibits AMPAR-mediated synaptic transmission presynaptically. Consistent with a presynaptic effect, $0.1 \mathrm{nM}$ leptin, a concentration that inhibits CA1 fEPSPs, did not alter spontaneous miniature EPSC amplitudes in CA1 neurons (39). A potential presynaptic mechanism based on a well-established leptin effect is BK channel activation $(11,13,36)$. Although BK channel activation contributes to action potential repolarization in CA3 pyramidal neurons, BK channel activation may only alter transmitter release at CA3-CA1 synapses under hyperexcitable conditions $(42,43)$. In addition, leptin activation of BK channels requires much higher leptin concentrations than needed to inhibit AMPAR-mediated synaptic transmission. Thus, BK channel activation may contribute to the anticonvulsant effect of leptin in vivo, but it may not be the primary mechanism by which leptin inhibits AMPAR-mediated synaptic transmission under normal conditions.

We also observed that leptin selectively inhibited the AMPAR component of the CA1 fEPSP and EPSC. A differential effect on the AMPA or NMDA component of an EPSP or EPSC is evidence of a postsynaptic effect $(44,45)$. Despite the marked differences in NMDAR and AMPAR sensitivity to glutamate, presynaptic manipulations do not selectively affect one component (45). A postsynaptic effect is consistent with the tendency for $0.1 \mathrm{nM}$ leptin to decrease depolarizations induced by iontophoretic applications of quisqualate, an AMPAR agonist, in CA1 neurons (39). Thus, our results suggest that leptin inhibits AMPAR-mediated synaptic transmission pre- and postsynaptically.

Leptin receptor activation of the JAK2/PI3K pathway inhibits AMPARmediated fEPSPs. Our results with 1 JAK2 inhibitor and 2 PI3K inhibitors and $d b / d b$ mice suggest that leptin inhibits AMPAergic synaptic responses by binding to its receptor and activating the JAK2/PI3K pathway. We examined this pathway because leptin enhances NMDAR-mediated responses (21) and activates BK and $\mathrm{K}_{\mathrm{ATP}}$ channels (13) via this pathway. We also examined this pathway because AMPARs complex with PI3K (22). Consequently, our results raise the possibility of a postsynaptic JAK2/PI3K-dependent mechanism for the inhibition of AMPAR-mediated synaptic transmission by leptin. However, PI3K activation causes AMPAR insertion (22, 23), which should result in enhanced synaptic transmission. Such a mechanism would account for some leptin concentrations enhancing long-term synaptic plasticity at excitatory synapses $(21,38-40)$. PI3K also regulates endocytosis $(46,47)$ and thereby may modulate AMPAR internalization (48). We speculate that different concentrations of leptin can produce opposing effects on AMPAR-mediated synaptic responses via a common PI3K signaling pathway (22) by differently modulating the sources and subcellular locations of leptin-dependent intracellular calcium changes.

Conclusion. Our data support the hypothesis that leptin is an anticonvulsant in vivo because the leptin receptor activates the JAK2/PI3K pathway and inhibits AMPAR-mediated synaptic transmission by a pre- and postsynaptic mechanism. Leptin's potential as a clinically useful anticonvulsant is enhanced because i.n. administration increases brain leptin levels, and leptin inhibits focal and generalized seizures (8). Although other anticonvulsants inhibit glutamatergic transmission, leptin may afford a broader range of treatment strategies because it is a peptide. For example, gene delivery strategies (49) might enable inducible leptin expression in an epileptogenic cortical region refractory to conventional anticonvulsants and not amenable to surgical treatment. Dietary modifications can increase systemic leptin levels $(16,17)$, and its transport into the brain may be enhanced by manipulating its endogenous transporters (7). Our results highlight leptin's potential for treating epilepsy by targeting brain leptin receptors and underscore the importance of understanding its regulation and physiological actions in the CNS.

\section{Methods}

Animals. Male Sprague-Dawley rats, Swiss-Webster mice, and CD-1 mice were purchased from Charles River Laboratories. Male $d b / d b$ (Stock 000642) and C57BLKS/J (Stock 000662) mice were purchased from Jackson Laboratory. Animal care and experimentation methods conformed to the Public Health Service Guide for the Care and Use of Laboratory Animals and the American Veterinary Medical Association Panel on Euthanasia Guidelines and were approved by the Washington University School of Medicine Animal Studies Committee.

Tissue preparation for electrophysiology. Primary dissociated hippocampal cultures were prepared from E15 Swiss-Webster mouse embryos on glass coverslips with preapplied glial feeder layers as described previously (50). Cells were used for patch-clamp recordings between 9 and 14 days in vitro. Hippocampal slices were prepared as described previously (51) from 6- to 8-week-old mice for extracellular recordings and from 3-week-old mice for whole-cell recording. Mice were killed under halothane at approximately the same time each morning because of leptin's diurnal variation. Brains were rapidly removed; placed in ice-cold ACSF consisting of $124 \mathrm{mM} \mathrm{NaCl}$, $5 \mathrm{mM} \mathrm{KCl}, 2.5 \mathrm{mM} \mathrm{CaCl}_{2}, 1.3 \mathrm{mM} \mathrm{MgCl}_{2}, 1.3 \mathrm{mM} \mathrm{NaH}_{2} \mathrm{PO}_{4}, 22 \mathrm{mM}$ $\mathrm{NaHCO}_{3}$, and $10 \mathrm{mM}$ glucose; and saturated with $95 \% \mathrm{O}_{2} / 5 \% \mathrm{CO}_{2}$ to a $\mathrm{pH}$ of 7.4. Transverse hippocampal slices $(400 \mu \mathrm{m})$ were prepared with a vibratome and incubated for at least 1 hour in ACSF at room temperature before the recording experiments were conducted.

Materials. Recombinant mouse leptin, D-APV, and the disodium salt of CNQX were purchased from Sigma-Aldrich. AG490, LY294002, and wortmannin were obtained from Calbiochem. Leptin stock solution consisted of $1 \mathrm{mg}$ lyophilized leptin solubilized in $0.5 \mathrm{ml} 15 \mathrm{mM} \mathrm{HCl}$ followed by the addition of $0.3 \mathrm{ml} 7.5 \mathrm{mM} \mathrm{NaOH}$ to raise the $\mathrm{pH}$ to about 5.2. The resulting stock solution was diluted in ACSF for cortical injection or in vitro electrophysiology experiments. To enhance CNS absorption after i.n. leptin administration (9), $1 \mathrm{mg}$ lysophosphatidylcholine (LPC; Sigma-Aldrich) was dissolved in $0.2 \mathrm{ml} 0.9 \%$ saline and mixed with $0.8 \mathrm{ml}$ of the leptin stock solution to a final concentration of $1 \mathrm{mg} / \mathrm{ml}$ leptin and $0.1 \%$ LPC.

Leptin assay. Serum and brain leptin levels were measured with the use of a commercial mouse ELISA kit (EZML-82K; Linco Research/Millipore Corp.). Leptin standards containing concentrations below $0.1 \mathrm{ng} / \mathrm{ml}$ were indistinguishable from the blanks, which indicated that the lower limit of detection is $0.1 \mathrm{ng} / \mathrm{ml}$ leptin. Therefore, all samples with readings below the average $3 \mathrm{SDs}$ for a blank were considered to have an undetectable leptin level, i.e., less than $0.1 \mathrm{ng} / \mathrm{ml}$ leptin. Brain or serum samples with higher than the maximum quantifiable level of leptin were diluted with assay buffer to obtain measurements within the range of the leptin standards in the kit, and values were calculated using the appropriate dilution factor. 
Mice were deeply anesthetized, and then a thoracotomy was performed to expose the heart. Blood was obtained by right atrium puncture and centrifuged at $15,900 \mathrm{~g}$ for 15 minutes at $4^{\circ} \mathrm{C}$. Next, intracardiac perfusion was performed via the left ventricle using cold $\left(0-4^{\circ} \mathrm{C}\right)$ PBS for 5-7 minutes, which was followed by brain removal. Pieces of frontal-parietal cerebral cortex and serum samples were immediately frozen on dry ice and stored at $-80^{\circ} \mathrm{C}$ until processed. Brain leptin levels were measured in some animals that received PTZ. These animals were not perfused, but control experiments showed that the leptin from the blood remaining in the nonperfused brain did not produce detectable brain leptin levels.

The leptin ELISA was performed on brain and serum samples according to the manufacturer's instructions. Brain levels were measured in samples $(-30-50 \mathrm{mg})$ prepared by mixing with $10 \mathrm{ml}$ lysis buffer per $1 \mathrm{mg}$ tissue. Lysis buffer consisted of $160 \mathrm{mM} \mathrm{KCl}, 25 \mathrm{mM}$ HEPES, and $1 \%$ Triton X-100. Samples were sonicated and mixed on a micro-rotator for 1 hour and then centrifuged for 20 minutes at $4^{\circ} \mathrm{C}$ at $15,900 \mathrm{~g}$. The supernatant was stored at $-80^{\circ} \mathrm{C}$ until analyzed. For leptin measurements, different dilutions of supernatant were made with assay buffer from the kit. Leptin levels in these samples of brain tissue were normalized to protein levels, which were determined using a commercially available kit (Micro BCA Protein Assay Kit; Pierce Biotechnology Inc.). All measurements were done in triplicate.

Neocortical seizure model. Four- to six-week-old male Sprague-Dawley rats were anesthetized with halothane (4\%) and then placed on a stereotaxic frame (David Kopf Instruments). A burr hole was drilled over the left hemisphere at a site $2 \mathrm{~mm}$ anterior to the bregma and $2.5 \mathrm{~mm}$ lateral to midline with a dental drill. After surgery, halothane was reduced to $1 \%-2 \%$ and $1 \mathrm{ml}$ ACSF containing $12.5 \mathrm{mM} 4 \mathrm{AP}(12.5 \mathrm{nmol})$ was injected from a glass micropipette (tip diameter: $100 \mu \mathrm{m}$ ) into the motor cortex $0.5 \mathrm{~mm}$ deep to the cortical surface with a commercial injector (Nanoject; Drummond Scientific). This model produces frequent repetitive seizures narrowly localized to the site of injection (24). Leptin-treated rats were injected with $1 \mathrm{ml}$ ACSF containing $12.5 \mathrm{mM} 4 \mathrm{AP}$ and $39 \mu \mathrm{M}$ leptin (39 pmol). Two screw electrodes were placed symmetrically over each hemisphere and differentially recorded the EEG in a referential montage with the use of standard AC EEG amplifiers (Grass-Telefactor). The EEG was digitized $(200 \mathrm{~Hz})$ and stored with the use of PC-based commercial hardware (Digidata and Axoscope; Axon Instruments). EEG recordings started 15 minutes before and ended 90 minutes after the 4AP injection. The EEG was visually analyzed by a reviewer blinded to the experimental protocol to determine the number of seizures in a record and seizure duration. A seizure was defined as a discrete electrographic event with an onset consisting of low-amplitude, high-frequency discharge followed by an evolving rhythmic, repetitive, high-amplitude discharge with a distinct termination.

PTZ generalized seizure model. Six- to eight-week-old male CD-1 mice were divided into a vehicle-treated control group and a leptin-treated group. A $20-\mathrm{mg} / \mathrm{ml} \mathrm{PTZ}$ stock was made by using sterile $0.9 \%$ saline, and each mouse received $75 \mathrm{mg} / \mathrm{kg}$ PTZ via i.p. injection. Leptin-treated rats received 8, 80, or $800 \mu \mathrm{g} / \mathrm{kg}$ in $0.1 \%$ LPC i.n. 30 minutes before PTZ administration. Control mice received LPC vehicle without i.n. leptin. All mice, regardless of the leptin dose administered, received a total volume of $20 \mu$ l. An observer, blinded to the treatment administered, measured the latency to the onset of the first generalized convulsive seizure as assessed behaviorally.
Electrophysiology experiments. Hippocampal slices were transferred to a submerged recording chamber (Warner Instruments) and perfused continuously at a rate of $3 \mathrm{ml} / \mathrm{min}$ with ACSF (see above) at $30^{\circ} \mathrm{C}$. Glass electrodes filled with $2 \mathrm{M} \mathrm{NaCl}$ (resistance: 3-5 M $\Omega$ ) were used to record fEPSPs from CA1 stratum radiatum. EPSPs were evoked via stimulation of the Schaffer collateral pathway through a bipolar electrode (David Kopf Instruments) at a frequency of $0.0167 \mathrm{~Hz}$. In all experiments, a stimulus intensity that evoked an EPSP with $50 \%$ of the maximal slope was used. The fEPSP slopes obtained during 15-20 minutes of stable baseline recording were averaged and then used to normalize fEPSP slopes during drug application and washout to combine data from different brain slices. EPSCs were recorded in voltage-clamp configuration from individual CA1 pyramidal neurons in hippocampal slices prepared as above from P21-P28 male CD-1 mice. Neurons were identified by infrared differential interference contrast videomicroscopy (52). The ACSF was slightly modified for whole-cell recording in slices to contain $2 \mathrm{mM}$ $\mathrm{CaCl}_{2}$ and $1 \mathrm{mM} \mathrm{MgCl}_{2}$. NMDAR-mediated EPSCs were isolated by adding $10 \mu \mathrm{M}$ NBQX. Patch electrodes for slice recording were filled with an internal solution containing $140 \mathrm{mM}$ potassium gluconate, $5 \mathrm{mM} \mathrm{NaCl}$, $1 \mathrm{mM} \mathrm{CaCl}_{2}, 2 \mathrm{mM} \mathrm{MgATP}, 10 \mathrm{mM}$ EGTA, and $10 \mathrm{mM}$ HEPES (pH 7.3). Whole-cell recording from hippocampal neuron cultures were performed by using an internal solution containing $\mathrm{mM} 140 \mathrm{mM}$ potassium gluconate, $4 \mathrm{mM} \mathrm{NaCl}, 0.5 \mathrm{mM} \mathrm{CaCl}_{2}$, 2 mM MgATP, $0.5 \mathrm{mM} \mathrm{Na}_{2} \mathrm{GTP}, 5 \mathrm{mM}$ EGTA, and $10 \mathrm{mM}$ HEPES ( $\mathrm{pH}$ 7.2) and an external solution containing $140 \mathrm{mM} \mathrm{NaCl}, 5 \mathrm{mM} \mathrm{KCl}, 1.5 \mathrm{mM} \mathrm{CaCl} 2,1 \mathrm{mM} \mathrm{MgCl} 2,10 \mathrm{mM}$ HEPES, and $10 \mathrm{mM}$ glucose ( $\mathrm{pH}$ 7.3). Analog data were obtained with an Axopatch 200B amplifier, digitized at $10 \mathrm{kHz}$, and analyzed with an Axon Instruments Digidata 1322A and pClamp9 (Molecular Devices).

Statistics. All data are presented as the mean \pm SD. Statistical analyses were performed by using paired or unpaired 2-tailed $t$ tests with appropriate corrections as indicated; ANOVA followed by Tukey-Kramer's or Kruskal-Wallis with Dunn's post test were used for comparisons between multiple groups. Statistical significance was set at $P<0.05$.

\section{Acknowledgments}

We are grateful to Mary Beth Finn and David M. Holtzman for helping us measure brain leptin levels. This work was supported by grant 1-2004-594 from the Juvenile Diabetes Foundation (to K.A. Yamada), grant NIH NS 042744 (to K.A. Yamada), grant NS 058597 (to L.L. Thio), the Epilepsy Foundation (to L.L. Thio), grant NIH R01 NS 042936 (to S.M. Rothman and X.-F. Yang), grant NIH R01 NS056872 (to M. Wong), and grant P30 NS057105 from the Neuroscience Blueprint Core. The work cited in this publication was performed in a facility supported by National Center for Research Resources grant C06 RR015502.

Received for publication June 15, 2007, and accepted in revised form October 24, 2007.

Address correspondence to: Kelvin A. Yamada, Department of Neurology, Box 8111, Washington University School of Medicine, 660 South Euclid Avenue, St. Louis, Missouri 63110, USA. Phone: (314) 454-6120; Fax: (314) 454-2523; E-mail: yamadak@wustl.edu.
1. Vezzani, A., Sperk, G., and Colmers, W.F. 1999. Neuropeptide Y: emerging evidence for a functional role in seizure modulation. Trends Neurosci. 22:25-30.

2. Dube, C., Brunson, K.L., Eghbal-Ahmadi, M., Gonzalez-Vega, R., and Baram, T.Z. 2005. Endogenous neuropeptide Y prevents recurrence of experimental febrile seizures by increasing seizure threshold.
J. Mol. Neurosci. 25:275-284.

3. Brunson, K.L., Avishai-Eliner, S., and Baram, T.Z. 2002. ACTH treatment of infantile spasms: mechanisms of its effects in modulation of neuronal excitability. Int. Rev. Neurobiol. 49:185-197.

4. Brunson, K.L., Khan, N., Eghbal-Ahmadi, M., and Baram, T.Z. 2001. Corticotropin (ACTH) acts directly on amygdala neurons to down-regulate corticotropin-releasing hormone gene expression. Ann. Neurol. 49:304-312.

5. Mazarati, A.M. 2004. Galanin and galanin receptors in epilepsy. Neuropeptides. 38:331-343.

6. Mackay, M.T., et al. 2004. Practice parameter: medical treatment of infantile spasms: report of the American Academy of Neurology and the Child Neurology Society. Neurology. 62:1668-1681. 
7. Banks, W.A., et al. 2004. Triglycerides induce leptin resistance at the blood-brain barrier. Diabetes. 53:1253-1260.

8. Fliedner, S., Schulz, C., and Lehnert, H. 2006. Brain uptake of intranasally applied radioiodinated leptin in Wistar rats. Endocrinology. 147:2088-2094.

9. Shimizu, H., Oh, I., Okada, S., and Mori, M. 2005. Inhibition of appetite by nasal leptin administration in rats. Int. J. Obes. (Lond.). 29:858-863.

10. Hakansson, M.L., Brown, H., Ghilardi, N., Skoda, R.C., and Meister, B. 1998. Leptin receptor immunoreactivity in chemically defined target neurons of the hypothalamus. J. Neurosci. 18:559-572.

11. Shanley, L.J., O’Malley, D., Irving, A.J., Ashford, M.L., and Harvey, J. 2002. Leptin inhibits epileptiform-like activity in rat hippocampal neurones via PI 3-kinase-driven activation of BK channels. J. Physiol. 545:933-944.

12. Carlo, A.S., Meyerhof, W., and Williams, L.M. 2007. Early developmental expression of leptin receptor gene and [125I]leptin binding in the rat forebrain. J. Chem. Neuroanat. 33:155-163.

13. Shanley, L.J., Irving, A.J., Rae, M.G., Ashford, M.L., and Harvey, J. 2002. Leptin inhibits rat hippocampal neurons via activation of large conductance calcium-activated $\mathrm{K}+$ channels. Nat. Neurosci. 5:299-300

14. Harvey, J. 2003. Novel actions of leptin in the hippocampus. Ann. Med. 35:197-206.

15. Durakoglugil, M., Irving, A.J., and Harvey, J. 2005 Leptin induces a novel form of NMDA receptordependent long-term depression. J. Neurochem. 95:396-405.

16. Kinzig, K.P., Scott, K.A., Hyun, J., Bi, S., and Moran, T.H. 2005. Altered hypothalamic signaling and responses to food deprivation in rats fed a low-carbohydrate diet. Obes. Res. 13:1672-1682.

17. Thio, L.L., Erbayat-Altay, E., Rensing, N., and Yamada, K.A. 2006. Leptin contributes to slower weight gain in juvenile rodents on a ketogenic diet. Pediatr. Res. 60:413-417.

18. Vining, E.P., et al. 1998. A multicenter study of the efficacy of the ketogenic diet. Arch. Neurol. 55:1433-1437.

19. Ayyildiz, M., Yildirim, M., Agar, E., and Baltaci, A.K. 2006. The effect of leptin on penicillin-induced epileptiform activity in rats. Brain Res. Bull. 68:374-378.

20. Irving, A.J., Wallace, L., Durakoglugil, D., and Harvey, J. 2006. Leptin enhances NR2B-mediated $N$-methyl- $d$-aspartate responses via a mitogen-activated protein kinase-dependent process in cerebellar granule cells. Neuroscience. 138:1137-1148.

21. Shanley, L.J., Irving, A.J., and Harvey, J. 2001. Leptin enhances NMDA receptor function and modulates hippocampal synaptic plasticity. J. Neurosci. 21:RC186.

22. Man, H.Y., et al. 2003. Activation of PI3-kinase is required for AMPA receptor insertion during LTP of mEPSCs in cultured hippocampal neurons. Neuron. 38:611-624.
23. Baxter, A.W., and Wyllie, D.J.A. 2006. Phosphatidylinositol 3 kinase activation and AMPA receptor subunit trafficking underlie the potentiation of miniature EPSC amplitudes triggered by the activation of L-type calcium channels. J. Neurosci. 26:5456-5469

24. Yang, X.F., and Rothman, S.M. 2001. Focal cool ing rapidly terminates experimental neocortical seizures. Ann. Neurol. 49:721-726.

25. Stables, J.P., et al. 2002. Models for epilepsy and epileptogenesis: report from the NIH workshop, Bethesda, Maryland. Epilepsia. 43:1410-1420.

26. Mangan, P.S., and Kapur, J. 2004. Factors underlying bursting behavior in a network of cultured hippocampal neurons exposed to zero magnesium. J. Neurophysiol. 91:946-957.

27. Goodkin, H.P., Yeh, J.L., and Kapur, J. 2005. Status epilepticus increases the intracellular accumulation of GABAA receptors. J. Neurosci. 25:5511-5520.

28. Fruhbeck, G. 2006. Intracellular signalling pathways activated by leptin. Biochem. J. 393:7-20.

29. Bjorbaek, C., and Kahn, B.B. 2004. Leptin signaling in the central nervous system and the periphery. Recent Prog. Horm. Res. 59:305-331.

30. Barnabe-Heider, F., et al. 2005. Evidence that embryonic neurons regulate the onset of cortical gliogenesis via cardiotrophin-1. Neuron. 48:253-265.

31. Yadav, A., Kalita, A., Dhillon, S., and Banerjee, K 2005. JAK/STAT3 pathway is involved in survival of neurons in response to insulin-like growth factor and negatively regulated by suppressor of cytokine signaling-3. J. Biol. Chem. 280:31830-31840.

32. Qiu, J., Cafferty, W.B., McMahon, S.B., and Thompson, S.W. 2005. Conditioning injury-induced spinal axon regeneration requires signal transducer and activator of transcription 3 activation. J. Neurosci. 25:1645-1653.

33. Hsu, H.T., et al. 2006. Leptin interferes with adrenocorticotropin/3', 5'-cyclic adenosine monophosphate (cAMP) signaling, possibly through a Janus kinase 2-phosphatidylinositol 3-kinase/Akt-phosphodiesterase 3-cAMP pathway, to down-regulate cholesterol side-chain cleavage cytochrome P450 enzyme in human adrenocortical NCI-H295 cell line. J. Clin. Endocrinol. Metab. 91:2761-2769.

34. Russo, V.C., Metaxas, S., Kobayashi, K., Harris, M., and Werther, G.A. 2004. Antiapoptotic effects of leptin in human neuroblastoma cells. Endocrinology. 145:4103-4112.

35. Dicou, E., Attoub, S., and Gressens, P. 2001. Neuroprotective effects of leptin in vivo and in vitro. Neuroreport. 12:3947-3951.

36. O’Malley, D., Irving, A.J., and Harvey, J. 2005. Leptin-induced dynamic changes in the actin cytoskeleton mediate the activation and synaptic clustering of BK channels. FASEB J. 19:1917-1919.

37. Chen, H., et al. 1996. Evidence that the diabetes gene encodes the leptin receptor: identification of a mutation in the leptin receptor gene in $\mathrm{db} / \mathrm{db}$ mice. Cell. 84:491-495.
38. Li, X.L., et al. 2002. Impairment of long-term potentiation and spatial memory in leptin receptor-deficient rodents. Neuroscience. 113:607-615.

39. Oomura, Y., et al. 2006. Leptin facilitates learning and memory performance and enhances hippocampal CA1 long-term potentiation and CaMK II phosphorylation in rats. Peptides. 27:2738-2749.

40. Wayner, M.J., Armstrong, D.L., Phelix, C.F., and Oomura, Y. 2004. Orexin-A (Hypocretin-1) and leptin enhance LTP in the dentate gyrus of rats in vivo. Peptides. 25:991-996.

41. Spanswick, D., Smith, M.A., Mirshamsi, S., Routh, V.H., and Ashford, M.L.J. 2000. Insulin activates ATP-sensitive $\mathrm{K}^{+}$channels in hypothalamic neurons of lean, but not obese rats. Nat. Neurosci. 3:757-758.

42. $\mathrm{Hu}, \mathrm{H}$., et al. 2001. Presynaptic $\mathrm{Ca}^{+}$-activated $\mathrm{K}^{+}$channels in glutamatergic hippocampal terminals and their role in spike repolarization and regulation of transmitter release. J. Neurosci. 21:9585-9597.

43. Raffaelli, G., Saviane, C., Mohajerani, M.H., Pedarzani, P., and Cherubini, E. 2004. BK potassium channels control transmitter release at CA3-CA3 synapses in the rat hippocampus. J. Physiol. (Lond.). 557:147-157.

44. Kauer, J.S. 1988. Real-time imaging of evoked activity in local circuits of the salamander olfactory bulb. Nature. 331:166-168.

45. Perkel, D.J., and Nicoll, R.A. 1993. Evidence for all-or-none regulation of neurotransmitter release: implications for long-term potentiation. J. Physiol. 471:481-500.

46. Lindmo, K., and Stenmark, H. 2006. Regulation of membrane traffic by phosphoinositide 3-kinases. J. Cell Sci. 119:605-614.

47. Wenk, M.R., and De Camilli, P. 2004. Inaugural article: protein-lipid interactions and phosphoinositide metabolism in membrane traffic: insights from vesicle recycling in nerve terminals. Proc. Natl. Acad. Sci. U. S. A. 101:8262-8269.

48. Collingridge, G.L., Isaac, J.T.R., and Wang, Y.T. 2004. Receptor trafficking and synaptic plasticity. Nat. Rev. Neurosci. 5:952-962.

49. Muller, F.J., Snyder, E.Y., and Loring, J.F. 2006. Gene therapy: can neural stem cells deliver? Nat. Rev. Neurosci. 7:75-84.

50. Thio, L.L., Shanmugam, A., Isenberg, K., and Yamada, K. 2003. Benzodiazepines block alpha2containing inhibitory glycine receptors in embryonic mouse hippocampal neurons. J. Neurophysiol. 90:89-99.

51. Thio, L.L., Wong, M., and Yamada, K.A. 2000. Ketone bodies do not directly alter excitatory or inhibitory hippocampal synaptic transmission. Neurology. 54:325-331.

52. Wong, M., et al. 2003. Impaired glial glutamate transport in a mouse tuberous sclerosis epilepsy model. Ann. Neurol. 54:251-256. 